\title{
$\approx$ \\ EIN PALESTINAR I DET \\ LIBANESISKE PARLAMENTET? EIT INTERVJU MED AKTIVISTEN MANAL KORTAM
}

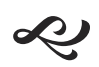

\begin{abstract}
Kva skjer når ein palestinar stiller til val i Libanon? Gjennom ein uortodoks valkampanje med namn «Vi eksisterer», ønskjer Kortam å synleggjere eit diskriminerande lovverk som har gjort Libanons palestinarar rettslause i fleire generasjonar.
\end{abstract}

ERLING LORENTZEN SOGGE

DET ER VALSESONG I LIBANON. ENDELEG. FAKTISK er det heile ni år sidan libanesarane sist heldt parlamentsval, i juni 2009. Ei rekke større og mindre kriser som har sendt landet inn i politisk vranglås gang på gang, har gjort at valet, som eigentleg skulle gå av stabelen i 2013, har vorte utsatt heilt fram til no. Langvarig usemje om danninga av ein ny vallov, sikkerheitsproblem og ustabilitet forårsaka av den syriske krigen og eit kvelande politisk vakuum som oppstod på grunn av parlamentet sin manglande evne til å velje ein president mellom åra 2014-2016, er berre nokre av faktorane som har ført til forseinkinga.

Skandalen som utspelte seg rundt statsminister Saad al-Hariri da hans viktigaste regionale allierte, Saudi-Arabia, i fjorhaust pressa han til å offentleggjere sin avgang mens han satt i husarrest i Riyadh, gjorde ikkje situasjonen enklare. ${ }^{1} \mathrm{Ni}$ år og ein ny vallov seinare, er det med eit letta sukk at libanesarane går til valurnene 6. mai.

Som ved kvart val, fylles radio- og tv-kanalar med snakk om taktikkeri, partiprogram, PR-stunt og spekulasjon rundt nye alliansar. Samtidig sprett det opp plakatar i alle byar med bildar av stivpynta kandidatar på stemmejakt. Ofte er det vanskeleg å skilje den eine frå den andre. Når det er sagt, så ser det politiske terrenget ut til å ha endra seg noko sidan 2009. Denne gongen blir den eldre garden i libanesisk politikk utfordra av ein stadig veksande straum av unge kandidatar som hungrar etter reform. Sidan 2005 har libanesisk politikk vore dominert av dei to rivaliserande valalliansane «8. mars» og «14. mars», som er leidd av Hizballah på den eine sida, og al-Hariris «Framtidsrørsle» på den andre. Begge vart i si tid oppretta grunna strid og usemje når det gjelde syrisk dominans over Libanon. Den nye generasjonen av kandidatar, derimot, ser ut til å trosse den regionale maktpolitikken ved å heller vie si interesse til

- Situasjonen for palestinarane blir verre for kvart år som går, fortel Manal Kortam. 


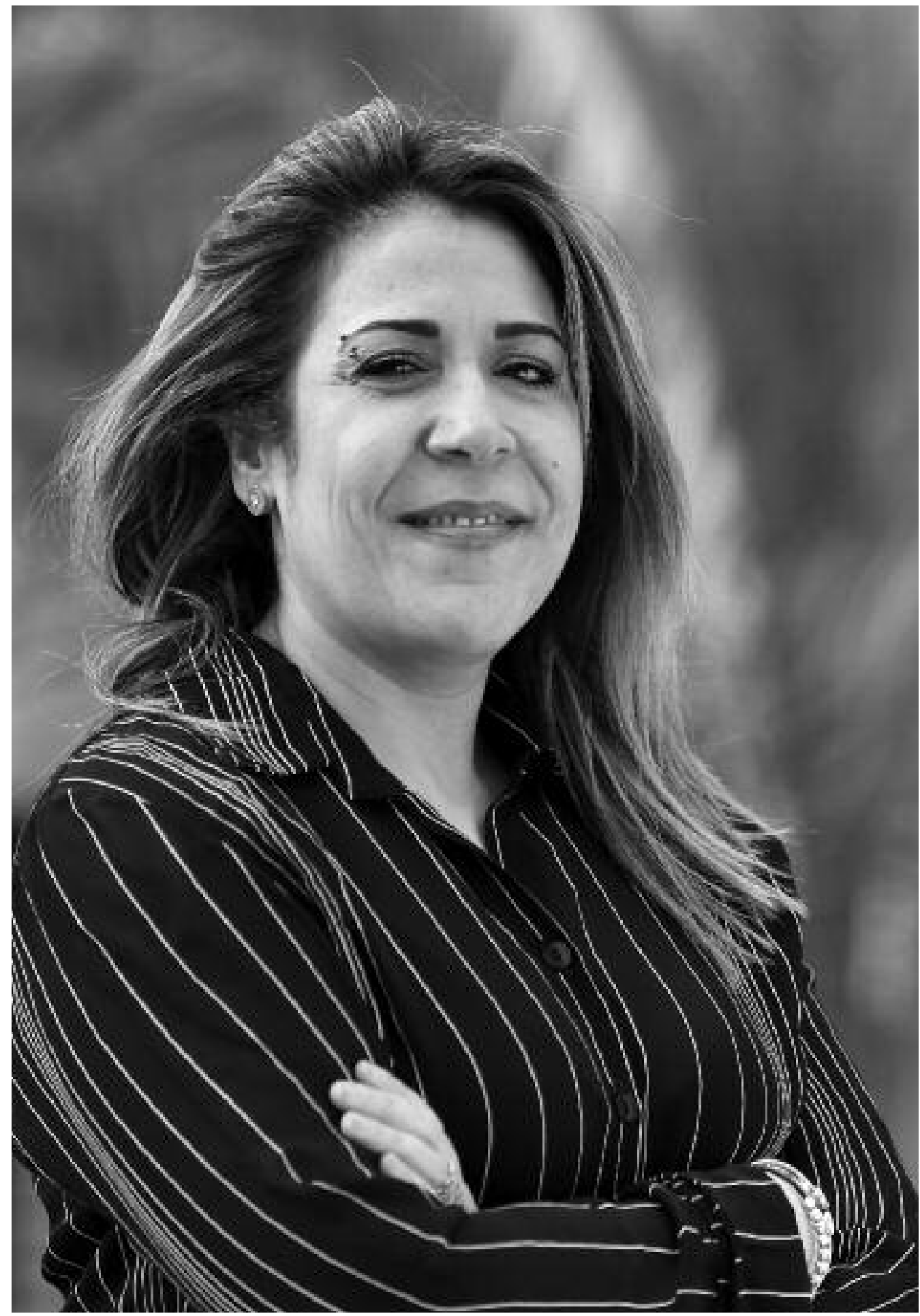


saker knytt til sivilsamfunn på det lokale planet. Det at den nye vallova erstattar det tidlegare majoritetssystemet ved å innføre proporsjonal stemmegiving gjennom 15 distrikt, gjer at lister med uavhengige kandidatar, som varierer mykje frå område til område, har byrja å ta over for dei store, monolittiske alliansane. ${ }^{2}$ Medan dei unge og uavhengige kandidatane manglar «wastaen» (patron-klient-nettverka) til dei gamle ringrevane, søker desse idealistane oppslutning ved å lansere kampanjar mot nepotisme, korrupsjon, ineffektivitet, og andre uting dei hevdar har hatt fritt spelerom i det libanesiske politiske systemet i fleire tiår.

For eksempel, fleire prominente aktivistar som vart kjende gjennom den storstilte «You Stink»kampanjen og anti-regjeringsdemonstrasjonane som skylte over Libanon i kjølvatnet av søppelkrisa i 2015, har no registrert seg som kandidatar i håp om å kunne endre systemet frå innsida. Desse har igjen slått seg saman med eit lappeteppe av miljøforkjemparar, teknokratar og aktivistar i ei fellesliste med namn «Min nasjon-koalisjonen» (Tahaluf watani). Det er også verdt å nemne at av dei 976 kandidatane som no stiller til val, finn vi 111 kvinner - dette i kontrast til dei tolv kvinnene som stilte til val for ni år sidan. ${ }^{3}$

Blant desse nye stemmane er Manal Kortam, ein palestinar frå Nord-Libanon. Hennar PRmateriale, som viser ei ung kvinne med augebrynpiercing og ei tatovert forarm, er tilsynelatande talande for dei demografiske endringane libanesisk politikk har gått igjennom dei siste få åra. Men ved nærare augekast, skil Kortam sin kampanje seg dramatisk frå sine aktivistkollegar. På hennar kampanjeplakat kan vi nemleg lese at ho stiller til val for «det palestinske setet i den tredje valkretsen» - eit sete som ganske enkelt ikkje eksisterer. Gjennom det ho kallar eit media-stunt med formål om å kaste lys over vilkåra til landets omtrent 200 ooo palestinarar, utfrodrar Kortam ei rekkje sosiale tabu om at Libanons flyktningbefolkning helst skal halde seg fråverande frå det offentlege ordskiftet, og at palestinarar ikkje skal blande seg i libanesiske saker. Som resultat har ho vore omgitt av ein mediestorm sidan lanseringa av kampanjen hennar, 16. mars. Stuntet hennar har vore flittig dekt av både nasjonal og internasjonal presse, og ho har utan tvil gjort inntrykk på libanesarane. Det fekk også Babylon erfare da vi ringte for å spørje henne ut om kampanjen tidleg i april, om lag ein månad før valet. Vi fekk tak i Kortam mens ho gjekk på fot heim frå jobb, men vi fekk knapt tid til å seie hallo før ho allereie hadde vorte stoppa tre gonger av ulike forbipasserande på gata som ville slå av ein prat med den provokative kandidaten.

\section{EKSISTERER}

«Ideen bak kampanjen kom frå ein samtale med ein ven,» seier Kortam på telefon frå Beirut. Venesirkelen hennar består i høg grad av aktivistar og organisasjonsfolk som i det siste har gått inn i politikken med sine respektive kampanjar, og på eit tidspunkt hadde nokre av dei byrja å vitse om at Kortam var den einaste i venegjengen som ikkje stiller til val i år. «I staden for påpeike at eg er palestinar og at eg ikkje har lov til å delta i libanesisk politikk, bestemte eg meg like godt for å ta utfordringa,» fortel Kortam. «Eg tenkte, kva ville skje om nokon som meg lanserte ein valkampanje? Det ville vere eit sjokk for mange, og derfor ein god sjanse til å ta opp spørsmål som dei andre kandidatane neglisjerer med tanke på flyktningar og spesielt palestinarane».

Gjennom hennar kampanje «Vi eksisterer», eller «Mawjudin» på arabisk, oppfordrar Kortam palestinarane i landet til å bli meir synlege og høgrøysta. Ho ønskjer å mane dei til å ikkje akseptere sin tildelte plass i marginen av den libanesiske staten. Dette er inga smal sak. I eit land der all politisk makt blir fordelt ut ifrå størringa på atten 
ulike religiøse/etniske grupper, blir palestinarane gjerne sett på som ein trussel mot den prekære balansen i det konsosialistiske politiske systemet som har danna grunnlaget for den moderne libanesiske staten sidan frigjeringa frå Frankrike i 1943. Da om lag hundretusen palestinarar flykta til Libanon under krigen i heimlandet i 1948, hadde dette skjøre sekteriske maktsystemet i liten grad plass til dei nye flyktningane, som nesten alle var sunni-muslimar. Blant dei libanesiske politiske

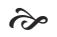 \\ Ho har ingen illusjonar om å faktisk få ein plass i det libanesiske parlamentet.}

partia, og spesielt den kristne høgresida, finn vi enno i dag ein nesten aksiomatisk aversjon mot å gi palestinarane borgarskap, og forbodet mot «tawtin» (naturalisering), som det heiter i libanesisk rettssjargong, er nedfelt i grunnloven. Dette er også grunnen til at palestinarane framleis nyt færre rettar i vertslandet enn kva ein besøkande turist gjer. Etter fire generasjonar i eksil, er det framleis umulig for palestinarane å ha eigedom, og dei har ingen arverett. Dessutan er dei lovlig låst ute frå om lag 36 yrke underlagt libanesiske fagforeiningar, og dei må gjennom ein krunglete, byråkratisk prosess for i det heile å få søkt om arbeidsløyve for eitt år om gongen - ein prosess mange libanesiske arbeidsgivarar ikkje tar seg bryet med. Slik sett er det ikkje overraskande at majoriteten bur innanfor dei tronge og fattigslege urbane slummane som utgjer dei tolv offisielle palestinske flyktningleirane, eller andre uoffisielle samlingar. Her overlever dei, om berre så vidt, på støtta dei mottar frå FNs kronisk underfinansierte støttebyrå for palestinarar, UNRWA.

«Situasjonen for palestinarane blir verre for kvart år som går,» fortel Manal Kortam. «Presset har berre auka etter utbrotet av den syriske flyktningkrisa. I augo til det libanesiske majoritetssamfunnet blir flyktningar sett på som infiltratørar og femtekolonnistar, og blir skulda for å utgjere ein trussel mot nasjonens sikkerheit. Alle unge palestinarar veks opp med dette stigmaet, jamvel om dei er fødde her og ikkje kjenner noko anna land. Dei vegrar seg for å snakke ut og å forlange betre vilkår fordi dei veit kva for skuldingar dei blir møtt med når de ytrar seg. Eg ønskjer å utfordre slike stigma, gjennom å mane palestinsk ungdom til å riste av seg all skam og å bli ein del av det offentlege ordskiftet - ved å bruke stemmen sin. Gjennom kampanjen min rettar eg også ein beskjed til den politiske eliten, om at ein vil aldri kunne oppnå nokon form for sosial rettferd $\mathrm{i}$ Libanon utan å inkludere palestinarane».

Trass i hennar provokative kampanjeplakat, kan Kortam avsløre at ho har ingen illusjonar om å faktisk få ein plass i det libanesiske parlamentet. Ho understreker at det ho og hennar støttespelarar kjempar for er grunnleggande sivile rettar for palestinarane. Politiske rettar, på den andre sida, slik som stemmerett, borgarskap og politisk deltaking, er ikkje einstemming ønskja av palestinarane i Libanon: Mange vil hevde at dei berre er gjestar i verstlandet, medan dei held fast på draumen om å ein dag kunne returnere til Palestina. «Det palestinarane krev på dette tidspunktet, er at å få leve i verdigheit og å bli behandle som menneske,» forklarer Kortam. «Libanon har ingenting på å tape på å gi dei eit minstemål av sivile rettar. Når det gjeld libanesarane, ønskjer eg å informere om at 'palestinarane er som dykk. Dei snakkar same språk og har levd her med dykk i nærare 70 år.' Kort summert, vi eksisterer.»

\section{RETTEN TIL Å GI NASJONALITET}

I forlenging av hennar kamp for palestinsk synleggjering, har Kortam også kasta seg inn i ein 
oppheta debatt om libanesiske kvinners manglande rett til å overføre statsborgarskap til sine born. I nærare tjue år har aktivistar kravd ei endring av den kontroversielle loven som stammar frå den franske mandatstida i 1925 - så langt utan hell. Nyleg overraska utanriksminister Gebran Bassil, ein av dei største bremseklossane i kampen for ein ny nasjonalitetslov, ved å kunngjere at han vil gå inn for eit endringsforslag som i visse tilfelle vil kunne gi libanesiske kvinner rett til å overføre sin nasjonalitet til borna sine. ${ }^{4}$ Bassils forslag kjem

\section{2 \\ Ein Hamas-leiar skildra ho som ein fare for den palestinske motstandskampen. $\infty$}

likevel med viktige atterhald: Denne retten vil ikkje inkludere kvinner som er gift med borgarar frå «nabolanda,» som i praksis betyr palestinarar og syrarar - eit unnatak naudsynt for å «bevare den libanesiske entiteten,» skal vi tru utanriksministeren. ${ }^{5}$

«Dette betyr at libanesiske kvinner som er gift med europearar får det betre, men dei som gifter seg med ein palestinar står framleis overfor utfordringa med å oppdra ikkje-libanesiske born utan rett til helsehjelp eller offentleg skolegang,» forklarar Kortam. «I dette lyset er det sjokkerande at utanriksministaren vår er frekk nok til å seie at libanesiske kvinner sjølve er fri til å velje kven dei vil gifte seg med. Kva for val er dette? Faktum er, at om ei kvinne skulle vele å gifte seg med ein mann av ein 'uønskt nasjonalitet' må ho akseptere at familien hennar i praksis blir statslaus. Dette er diskriminering. Det er ikkje berre eit problem for kvinner, det omfattar heile familien,» legg Kortam til, som sjølv arva sin fars palestinske flyktningstatus ved fødselen, jamvel om mora er libanesar. I følgje ein FN-rapport frå 2017, ${ }^{6}$ er Libanon i dag blant 26 land som ikkje behandlar kvinner på lik linje med menn når det gjeld å gi nasjonalitet til born. ${ }^{7}$ I Noreg vart ikkje kvinner likestilt med menn i nasjonalitetsspørsmålet før 1979. ${ }^{8}$

\section{Å MARSJERE TIL JERUSALEM}

Manal Kortams kamp for å gjere den rettslege kløfta mellom libanesarane og landets palestinar mindre, har blitt møtt med både begeistring og kritikk frå begge sider. Ein ting er klart: det er ikkje berre libanesarane som meiner hennar framgangsmåte er kontroversiell. Nyleg gjekk ein Libanon-basert Hamas-leiar ut i sosiale medium og åtvara mot Kortams kampanje for eit palestinsk sete i det libanesiske parlamentet, og skildra ho som ein fare for den palestinske motstandskampen. Denne logikken bygger på tanken om at ein integrasjon av flyktningane i det libanesiske samfunnet er på kant med kampen for retten til å returnere til Palestina, som er innlemma i FNs sikkerheitsrådresolusjon 194 og er eit sentralt krav for den palestinske leiarskapen. «Dette er veldig betente spørsmål. I det noverande politiske klimaet blir folk som meg, som nyttar utradisjonelle metodar for å fremme vår sak, ofte skulda for å ha uærlege motiv eller baktankar,» forklarar Kortam, som legg til at ho inviterte nemnde Hamas-leiar til ein offentleg debatt, men enno har til gode å høyre frå han.

Slike reaksjonar frå eigne rekker har likevel ikkje hindra Kortam frå å legge ut på ein publisitetsturne i landets palestinske flyktningleirar. Nyleg avla ho eit besøk til den nordlege al-Beddawi-leiren, som ligg i utkanten av hennar heimby Tripoli. «Tilbakemeldingane har vore utruleg fine. Palestinsk ungdom tar stadig kontakt og spør om korleis dei kan bidra og seier dei har tru på kampanjen min. Det er verkeleg hjartevermande å sjå at folk støtter saka, og at dei forstår poenget med det eg gjer. Når det kjem til stykke, gjer eg jo dette for deira skuld.» 
Når det er sagt, har heller ikkje leirturneen hennar vore fri for kontrovers. Ved besøket i alBeddawi-leiren, skapte Kortam, som har greskortodoks bakgrunn, furore ved å invitere leirbuarane til å feire palmesøndag saman med henne. Slike invitasjonar er ikkje kvardagskost i dei palestinske leirane, der sunni-muslimske autoritetar dominerer den religiøse sfæren. I tillegg, kan det nemnast at Tripoli som by er kjend for å huse ei rekke ultra-konservative salafistiske rørsler, som også har satt sitt preg på sosiale normer inne i leiren. «Nokon på sosiale media svara med å seie 'ikkje gå på akkord med religionen din ved å bli med Manal Kortam,» minnast sistnemnde. «Dette er absurd. For meg var dette ei feiring i palestinsk nasjonalistisk ånd. Dei som har litt kunnskap er klar over at palmesøndag var da Jesus rei inn i Jerusalem. Eg svara denne personen ved å seie at 'Dette er ei skam. No kan alle sjå at du ikkje har tenkt å bli med oss andre når vi marsjerer mot den palestinske hovudstaden'».

\section{FOLKERøRSLA HELD FRAM}

Manal Kortam vil ikkje få nokon stemmer under dette valet. Det er heller ingen grunn til å tru at Libanon vil opprette eit palestinsk sete i parlamentet i nær framtid. For sin del, er Kortam tilfreds med hennar rolle som provokatør og måten ho har tvinga andre kandidatar til å ta stilling til situasjonen til palestinarane før valet. Kortam avslører at «Vi eksisterer»-kampanjen vil halde fram sjølv etter at vallokala stenger 6. mai. «Så langt har kampanjen gått ut på fokusere på meg som kandidat, men etter valet vil bildet mitt bli fjerna. På sikt vil vi gi rom for andre stemmer og eksponere nye fjes. I løpet av dei siste få vekene har eg vore $\mathrm{i}$ kontakt med mange unge palestinarar som er ivrige på å bidra. Kampanjen vår vil på ingen måte stoppe. Han vil halde fram som ei folkerørsle,» konkluderer med Kortam med optimistisme i stemma. Mens ho rundar hjørnet til blokka der ho bur, går samtalen vår mot slutten. Men før vi får lagt på røret blir ho dratt kjensel på av ein nabo som skyt inn ein frekk kommentar om hennar palestinske kandidatur. «Dette er ikkje ein kandidatur, dette er ein revolusjon,» høgg Kortam tilbake kontant. «Om det er slik det heng saman ...» seier naboen etter å ha tenkt seg litt om, «da støttar eg deg. Bravo 'aleki».

\section{- $f$ •}

ERLING LORENTZEN SOGGE er redaktør for Babylon og stipendiat i Midtaustenstudiar ved Universitetet i Oslo.

1 Al-Hariri trakk seinare tilbake resignasjonen og er i skrivande stund framleis statsminister.

2 Mona Alami, "Lebanon's new electoral law could spell trouble for traditional parties," al-Monitor, 21. mars 2018. al-monitor.com/pulse/originals/2018/03/ lebanon-elections-new-law-hezbollah-resultsconstituency-win.html. (henta 26. april 2018).

3 Nour Samaha, "Lebanon elections pit old guard against new movement," Al-Monitor, 15. mars 2018.

4 Abby Sewell, "Lebanon nationality law set to change, but critics say doesn't go far enough," Middle East Eye, 3. april, 2018. al-monitor.com/pulse/ru/contents /articles/originals/2018/03/new-law-2018parliamentary-elections-civil-dynasties-lebanon.html. (Henta 24. april 2018)

5 The Daily Star, "Activists reject Bassil proposal for passing on nationality", The Daily Star, 22. mars 2018.

6 UNHCR, "Background Note on Gender Equality, Nationality Laws and Statelessness 2017," (2017), refworld.org/docid/58aff4d94.html. (Henta 24. april 2018)

7 For dei som vil vite meir om kvinners kamp for stats borgarskap i Midtausten, sjå Rania Maktabi, "Arabiske kvinners statsborgerskap", Babylon - Nordisk tidsskrift for Midtøstenstudier, no. 2 (2011): 6-21, http://dx.doi.org/10.5617/ba.4232

8 Elisabeth Lønnå, "Kvinners rettigheter i Norge fra 1945 til 1990-årene”, (Store norske leksikon, 2017): snl.no/Kvinners_rettigheter_i_Norge_fra_1945_ til_1990-\%C3\%A5rene (Henta 26. april 2018) 